\title{
Determining a Relationship between Licensing Status and Semi- Quantitative Risk Score for BC Dairy Processing Plants
}

Dilavar Rana ${ }^{1}$, Helen Heacock², Lorraine McIntyre ${ }^{3}$

1 Lead Author, B. Tech Student, School of Health Sciences, BC Institute of Technology, 3700 Willingdon Ave, Burnaby, BC V5G $3 \mathrm{H} 2$

2 Supervisor, School of Health Sciences, BC Institute of Technology, 3700 Willingdon Ave, Burnaby, BC V5G 3H2

3 Contributor, BC Center for Disease Control, 655 West 12th Avenue, Vancouver, BC V5Z 4R4

\begin{abstract}
Background: Following the 2014 Gort's Gouda Cheese Escherichia coli O157:H7 outbreak which resulted in one death and 28 illnesses, an examination of dairy processing plants (DPP) within British Columbia (BC) was undertaken. The intent of this examination was to efficiently allocate resources to ensure a lower likelihood of future outbreaks occurring in a BC DPP and to improve current knowledge regarding DPP practices. A risk-based approach to assessing inspection activities for DPPs was undertaken. As such, the purpose of the project was to create a semi-quantitative tool to assess inherent risk factors of DPPs, after which it would be used to determine appropriate inspection frequencies for these plants based on their risk scores. Finally, a comparison between provincially licensed and federally registered dairies was conducted in order to examine if there was a difference in risk between the two licensing statuses.

Methods: A semi-quantitative approach was used to characterize responses to a survey (Shi, 2014) conducted by the BCCDC between August and December 2014. This survey was sent to all DPPs $(n=54)$ operating in BC. Each survey question related to increasing information on conditions found in DPPs, after which a semi-quantitative assessment approach was used to assign a total risk inherent to each DPP due to the conditions found in the facility. The DPPs were then ranked against each other with respect to their risk scores in order to assess which facility was considered of higher risk. Facilities were grouped by their licensing status, provincially licensed or federally registered, and then compared against one another using a two variable t-test in NCSS 10. Semi-quantitative risk assessment was done using an Excel tool designed specifically for the present study.

Results: Complete data was obtained for $85 \%(n=46)$ of DPPs, with an equal number of provincial and federal DPPs used in the evaluation. Dairies were ranked against one another with respect to their total risk score. A statistically significant difference $(p=0.036)$ was found when comparing the inherent risk of provincial and federal DPPs, with federally registered dairies showing a lower total inherent risk score.

Conclusion: The information obtained from this study provided the BCCDC with a standardized risk-based inspection approach. Ranking of DPPs with respect to their inherent risk also allows inspectors to gain better understanding of present day dairies and their high risk issues. This reassessment allows for the development of more efficient inspection schedules in order to effectively allocate inspection resources and to increase the ability for inspectors to capture and prevent risks which would lead to foodborne illnesses.
\end{abstract}

Keywords: dairy, cheese, milk, semi-quantitative, risk assessment, British Columbia, Gort's Gouda Cheese, E. coli, BCCDC, outbreak, foodborne illness, environmental health, inspection

\section{Introduction}

Today's world requires a food processing industry which has the capacity to serve local and international markets. To ensure food processed by processing plants retains its integrity and shelf life there needs to be reliable controls in place. One 
example of a control is inspection of these plants, focusing on such aspects of food protection that include the flow of food, the processing of food as well as the plans for handling of food products. More frequent inspections of riskier establishments help to protect the integrity of the food product (Nikolic, 2012). Despite all the controls used, there is always an inherent risk to processing of any food product. Therefore, prioritizing inspections for plants which would pose a higher risk than those that would not is important to ensure a safe product of good quality. In the present study, a semi-quantitative risk assessment was used to characterize dairy plants in BC based on the risk inherent to the facility in order to ascertain if federally registered plants were of lower risk than provincially licensed ones. Since federally registered dairies export out of province and out of Canada, these dairies were considered to have a lower risk score due to stricter controls of food source and processing.

Risk assessment has been conducted in many industries, from engineering to food processing. For the food industry, other countries have already switched to a system which involves proportioning inspections based on risk assessments. These systems have been shown to prevent disease outbreaks and also have decreased total number of inspections. This resulted in lower costs for taxpayers as well as the dairy industry (FSA, 2011).

There are three types of risk assessment methods, qualitative, quantitative and the semi-quantitative which is also known as alternative method. Each of these methods fills a niche as they have their own advantages and disadvantages. All three methods are discussed in the present study.

\section{Literature Review}

Risk assessment strategies are made up of four steps which are used to determine the likelihood of a hazard causing a given level of harm. These parts are as follows:
1. Hazard Identification: In the first step, identification of any health hazards is conducted while incorporating information from policies or any other resource

2. Toxicological Assessment: This step involves evaluation of adverse health effects caused by the identified public health hazard

3. Exposure Assessment: This step refers to where the likelihood of the hazard(s) being present is estimated

4. Risk Characterization: In the final step, the risk is characterized by integrating the above to show who is at risk, what contributed most to that risk, and which intervention strategy would lead to the greatest reduction of risk. This gives assessors a complete and informative conclusion for risk assessment.

Risk assessment studies have used legislation, other research studies (Baghurst, 1999), epidemiological studies (Allain, 1998), statistics (ANZFA, 2001) and any other source of relevant data to complete the first three steps. The fourth step uses information from the first three in order to show the overall riskiness. Understanding what source of information can be used for the first three steps is crucial. This is because it is the only resource which can be used to create the likelihood and severity data required for semi-quantitative studies and for the data used in the calculation methods and models found in quantitative studies.

Using established data for risk assessments provide agencies with a process that can be applied in a scientific manner in order to inform them on how current policies can be changed to reduce risk. As such, they have been used in recent times to assess danger posed by pathogens, alter frequencies in inspection, and also evaluate the efficiency of already established risk assessment procedures (Fowle III, 2000). Examples of three types of risk assessment strategies are discussed below.

\section{Qualitative Risk Assessment}

In the food industry, the most commonly used qualitative risk assessment 
is Hazard Analysis and Critical Control Points (HACCP), a plan introduced by the National Aeronautics and Space Administration (NASA) which has allowed the food industry to develop programs to maintain and improve food integrity. While useful, its application is limited due to its reliance on potentially ambiguous qualitative data. As such, it cannot quantify the result of deviations or produce data measurement for public health impact (Buchanan, 1998). This has led to an increase in mathematical models to assess microbiological risks to public health related to food manufacturing. Qualitative risk assessments are appropriate for determination of high, medium and low risk steps (USDA, 2013)

\section{Quantitative Risk Assessment}

The Stepwise and Interactive Evaluation of Food Safety by an Expert System (SIEFE) is a quantitative risk assessment model which has been used in the past (Gerwen, 2001). SIEFE uses quantitative data to estimate risk factors in order to determine risk for a food product. This has been shown to overcome the shortcomings of HACCP. SIEFE still has downsides as this approach requires mathematical models. These models are complex and fall short of fully assessing risk factors when there is insufficient data (Gerwen, 2001). Quantitative risk assessments are best suited for identification and evaluation of food safety control points and to estimate the benefits of intervention strategies (USDA, 2013).

\section{Semi-Quantitative Risk Assessment}

An alternative model that has been

used in the past is the semi-quantitative risk characterization approach (FAO/WHO, 2009). This is a combination of the quantitative and qualitative risk assessment procedures and allows for risk to be evaluated based on both numerical and qualitative data. It is considered a stronger approach to assess and compare risk management strategies and is used in situations where increased efficiency in the use of resources to minimize the impact of risks is needed. These assessments allow a wide array of data to be interpreted for ranking against one another based on the evaluated risk. Thus this type of risk assessment is useful for determining DPPs which are of higher risk (USDA, 2013) as required by the present study. It is important to note that previous studies have suggested semi-quantitative risk assessments may bias risk managers towards possible consequences rather than accurate assessment of the overall risk, this leads to all risk being avoided despite the reality (Woodruff, 2005).

Risks are mapped into different logical and hierarchal categories according to their severity as defined by the likelihood of the risk occurring and by its health impact. Likelihood and impact data can be obtained from research or quantitative data results such as surveys. One disadvantage of semi-quantitative risk assessment is a potential loss of precision from the quantitative data set as information is fit into categories of specified ranges.

Semi-quantitative risk assessment calculations have been condensed into a variety of relatively easy to use tools that take the form of spreadsheets. These are easy to use as the risk manager selects a qualitative statement and inputs quantitative data to generate an overall risk to public health. However, these tools need to be carefully used as there are shortcomings which include the over simplification of the qualitative statements used. None-the-less, semi-quantitative risk assessment approach is considered to be more user-friendly than quantitative risk assessment while still being able to incorporate qualitative risk factor information (Ross, 2002).

\section{Case Studies}

A semi-quantitative approach in risk assessment was used to assess the risk of Mycobacterium bovis with respect to internation trade of cow's milk(Lake, 2009). A semi-quantitative approach for categorizing risk was used because the authors felt that since there was no prevalence information, there would be no way to establish risks for exposure and hazard characterization and a quantitative approach would produce incomplete results. By using epidemiological data instead, 
Mycobacterium bovis was compared to other food safety issues to allow risk managers to make appropriate decisions regarding the bacterium. The risks were characterized through looking at both the incidence and severity of the disease, which lead to the creation of a four category scoring chart for incidence and a three category scoring chart of severity. This resulted in the bacterium being given a high severity rating ( $>5 \%$ serious outcomes) with a low incidence rate ( $<1$ per 100,000 per year). The authors concluded that further risk management measures in addition to the pasteurization currently being used would be unnecessary with respect to $M$. bovis (Lake, 2009).

An additional study was conducted into establishment of a risk profile with respect to Toxoplasma gondii in New Zealand meat products from a variety of animals. This study examined factors involving the parasite, the population at risk, how prevalent it is and a wide variety of other factors in order to determine possible risk. This parasite can be transmitted to foetuses when a pregnant woman becomes infected and can lead to a variety of long term disease in children such as mental retardation, blindness or even death. In this study, severity and incidence were also considered, and it established that domestic meat in New Zealand would result in 66 birth defects due to toxoplasmosis each year (Lake, 2002).

In Japan, a semi-quantitative approach was used to assess and rank the milk industry's HACCP food safety management plans. Interviews of the quality assurance representatives from 13 companies were conducted. It was found that while the technological dependent procedures were of little risk, there was an issue with the administrative protocols, such as inadequate monitoring and verification (Sampers, 2012).

\section{Gort's Gouda Cheese Farm and Outbreak Response}

In 2013 an outbreak of E. coli O157:H7 was linked to Gort's Gouda Cheese Farm in Salmon Arm, BC (PHAC, 2013). This outbreak extended across
Canada and resulted in a total of 28 reported cases, 13 located within $\mathrm{BC}$. In response to the outbreak the $B C C D C$ has started to reassess dairies for their potential risk in order to improve their dairy inspection system, and create a new and updated inspection frequency schedule. The current system corrects and manages risks well, so improving inspections more so with respect to frequency and approach are expected to reduce risks and prevent large scale outbreaks from happening.

The BCCDC sent out a survey in August 2014 to all provincial dairies to be completed, with the intent to use the response data for a semi-quantitative risk assessment (BCCDC, Personal Communication, September 27 2014) The survey queried dairy operators over a wide range of questions including ones which relate to the conditions of the source of milk, food safety plans, dairy processing and processing controls, added ingredients, plant location and structure of premises as well as what is done with the finished product.

\section{Legislation}

In Section 20 of the Milk Industry Act, inspectors, as designated by the Minister, are given the power to allow them to enter any dairy and ensure compliance with legislation as frequently as possible. This means it is of utmost importance to develop a list of high to low risk dairies so that more time can be allocated through increased inspection frequency to those dairies which are considered to operate at relatively risky conditions. The act also lays out general procedures and expectations of dairies with respect to how they produce milk and how they can sell it (Milk Industry Act, 2014).

The Milk Industry Standards Regulation prescribes that farms must follow certain conditions in Part 2 of the regulations. These conditions comprise farm maintenance, construction, prevention of contamination and general cleanliness. Part 3 deals with storage of milk; Part 4 with sampling, testing and transportation; Part 5 with the general construction of dairy plants 
and part 6 deals with milk pasteurization (Milk Industry Reg., 2014).

The BCCDC survey captured conditions from both the act and regulation into its questionnaire design so that the data could be used for risk assessment. These two acts also fall under section 152 of the consequential amendments found in the Public Health Act (HA, 2014). This act allows EHOs to be involved in cases of outbreaks and will be discussed below. Based on currently available research, the method that would be best suited for ranking $B C$ dairies on their risk score would be a semi-quantitative risk assessment. As shown above in case studies, there is sufficient evidence that this approach can be successfully used for BC DPPs, in order to improve the current inspection schedule and further promote public health protection with better resource allocation. The risk ranking approach can be further used to determine whether provincially licensed or federally registered DPPs have statistically significant differences in risks inherent to the facility.

\section{Methods}

The BCCDC survey comprises questions which address concerns from the 2013 E. coli outbreak investigation of Gort's Gouda Cheese Farm (PHAC, 2013). In early 2014 , this was sent to all DPPs in the province of $B C$ in order to create a new riskbased inspection frequency. A risk hazard rating was attributed to each possible answer from the survey and each rating was given a specified numerical risk score. The total risk score for each DPP was then ranked against the risk scores for other dairies to create a risk based ranking of all the dairies in BC (BCCDC, 2014). This process was done by copy and pasting survey data into an excel sheet which was scripted to automatically perform all of these functions with minimal input required by the risk assessor. All information is viewable by the assessor who can then adjust parameters prior to ranking if necessary. The risk ratings were established using any available legislation, policies, guidelines, research, expert opinion or any source of available information which could be used to relate a situation to a category of risk. The excel sheet characterized risk based on a semi-quantitative method, where the above information described the risk of a condition by establishing its likelihood of occurrence and its impact to human health (Fowle, 2000). The risk categories and their numerical risk score can be found below in Table 1.

Table 1 - Specified Numerical Values and Description of the Risk Categories Used

\begin{tabular}{|c|c|c|}
\hline $\begin{array}{l}\text { Risk } \\
\text { Category }\end{array}$ & Value & Description \\
\hline None & 0 & $\begin{array}{l}\text { A condition which } \\
\text { has no risk } \\
\text { associated with it }\end{array}$ \\
\hline Low & 1 & $\begin{array}{l}\text { A condition } \\
\text { producing a risk that } \\
\text { has a low likelihood } \\
\text { or impact }\end{array}$ \\
\hline Medium & 2 & $\begin{array}{l}\text { A condition } \\
\text { producing a risk that } \\
\text { has a high likelihood } \\
\text { or impact }\end{array}$ \\
\hline High & 3 & $\begin{array}{l}\text { A condition } \\
\text { producing a risk that } \\
\text { has a high likelihood } \\
\text { and impact }\end{array}$ \\
\hline
\end{tabular}

The numerical scores above allowed for the DPPs to be ranked against each other based on their total risk according to the research conducted. In addition to this ranking, licensing information was included for each dairy in order to determine if licensing status showed a significant increase in potential risk for a dairy with respect to the conditions on the survey.

\section{Plant Inclusion and Exclusion Criteria}

In the present study, 46 of the 54 BC DPPs which the survey was sent to were able to be included (85\%). Eight dairies did not respond to the survey and thus were not included due to time constraints imposed on the author. Additional exclusion characteristics by the BCCDC include (1) if they were not currently licensed or actively processing, and (2) if more than one response from that dairy was received. Survey data was received blinded with 
contact information to remove sources of bias as well as due to privacy issues.

(McIntyre, 2014).

\section{Data Collection and Entry}

All $B C$ dairies were informed to complete the BCCDC's online survey. The survey was posted on a BCCDC website designed to create surveys, monitor and output the final results into an excel tool created by the author. The survey subsections are described below Table 2 along with the score range that each subsection contributed to the total risk score.

Table 2 - Risk Score Proportions

\begin{tabular}{|lcc|}
\hline \multicolumn{1}{|c|}{ Subsection } & Min & Max \\
\hline $\begin{array}{l}\text { Company } \\
\text { Information }\end{array}$ & 0 & 8 \\
Plant Location & 0 & 35 \\
Milk Source & 4 & 86 \\
$\begin{array}{l}\text { Non-Dairy } \\
\text { Ingredients } \\
\text { Plant Premise }\end{array}$ & 0 & 15 \\
$\begin{array}{l}\text { Food Safety } \\
\text { Management } \\
\text { Dairy }\end{array}$ & 1 & 51 \\
$\begin{array}{l}\text { Processing and } \\
\text { Processing }\end{array}$ & 0 & 33 \\
$\begin{array}{l}\text { Control } \\
\text { Product } \\
\text { Information }\end{array}$ & 0 & 94 \\
$\begin{array}{l}\text { Finished Product } \\
\text { Status }\end{array}$ & 6 & 46 \\
\hline
\end{tabular}

The use of the excel tool to conduct a semi-quantitative risk assessment ensured there was consistency during data entry. This is due to the interpretation being based on scripting within Excel rather than it relying on manual entry. This minimized the likelihood of errors being introduced during data entry. DPPs were ranked on their Dairy ID number, total risk score, all subsections risk scores and their licensing status.

Dairy ID and total risk score were used to determine which dairies would require a higher inspection frequency.
Additional information included subsection risk scores to show what area contributed most to a dairy's overall risk score.

\section{Reliability and Validity}

A total of 23 federally registered and 23 provincially licensed DPPs were surveyed. There are a total of 54 dairies in $\mathrm{BC}$, so the data used made up the majority of the sample set in BC. In addition to this, the method of data collection and analysis was kept constant to ensure no internal biases were formed when carrying out these aspects of the present study. The only challenge with respect to reliability was how well the tool itself was scripted to take into account all possible conditions and the synergistic effects where two conditions together may have a higher risk score than either one alone.

Validity was established through the use of a variety of different sources of information in order to establish the risk categories for each condition. The author used legislation, news on previous dairy outbreaks, personal communication with those who are responsible for inspection of these facilities, primary research, outcomes of previous dairy based outbreaks, policies, guidelines and any other source of pertinent information as mentioned previously. Due to the current nature of these sources of information, these categories of risk would not be invalid. Validity was also increased as the data was recent as of 2015 so the present study was based on analysis of the operations at the time of writing.

Due to the above considerations and the study design, the author considers both the validity and reliability to be high with respect to determining if there was a connection between risk score and licensing status Ethical Considerations of Study

The risk scores were intended to only serve the BCCDC and not for public use. As such, the present study omitted identifying information on dairies in order to prevent bias and to ensure consistency with privacy protection requirements. The author was also unable to trace any information back to a specific dairy as the BCCDC had only supplied the author with identification numbers that gave no such contact 
information. The omission of information did not compromise the present study since it answered any potential questions of bias.

\section{Results}

Data were collected and organized in excel and then put through rudimentary analysis tools. NCSS was used for inferential statistics in order to determine significance of the data set, as seen below in Section 3.3 (NCSS, 2007). Two variables were considered: the licensing status of the facility (nominal data) and the total risk score attributed to that facility (numerical data). Table 3 below shows the descriptive statistics with respect to the variables.

Table 3 - Descriptive Data on Risk Scores separated by Licensing Status

\begin{tabular}{lrlr}
\hline $\begin{array}{l}\text { Provincially Licensed } \\
\text { Dairies Risk Score }\end{array}$ & \multicolumn{2}{c}{ Federally Registered Dairies } \\
\hline Mean & 144.96 & Mean & 131.96 \\
Standard Error & 5.08 & Standard Error & 5.03 \\
Median & 142 & Median & 127 \\
Mode & 115 & Mode & 109 \\
Standard Deviation & 24.35 & Standard Deviation & 24.14 \\
Sample Variance & 592.68 & Sample Variance & 582.68 \\
Kurtosis & -1.36 & Kurtosis & -0.82 \\
Skewness & 0.24 & Skewness & 0.50 \\
Range & 76 & Range & 80 \\
Minimum & 112 & Minimum & 100 \\
Maximum & 188 & Maximum & 180 \\
Sum & 3334 & Sum & 3035 \\
Count & 23 & Count & 23 \\
Confidence & & Confidence & 10.44 \\
Level(95.0\%)
\end{tabular}

Data was obtained using t-test function in Excel descriptive statistics data analysis add-in

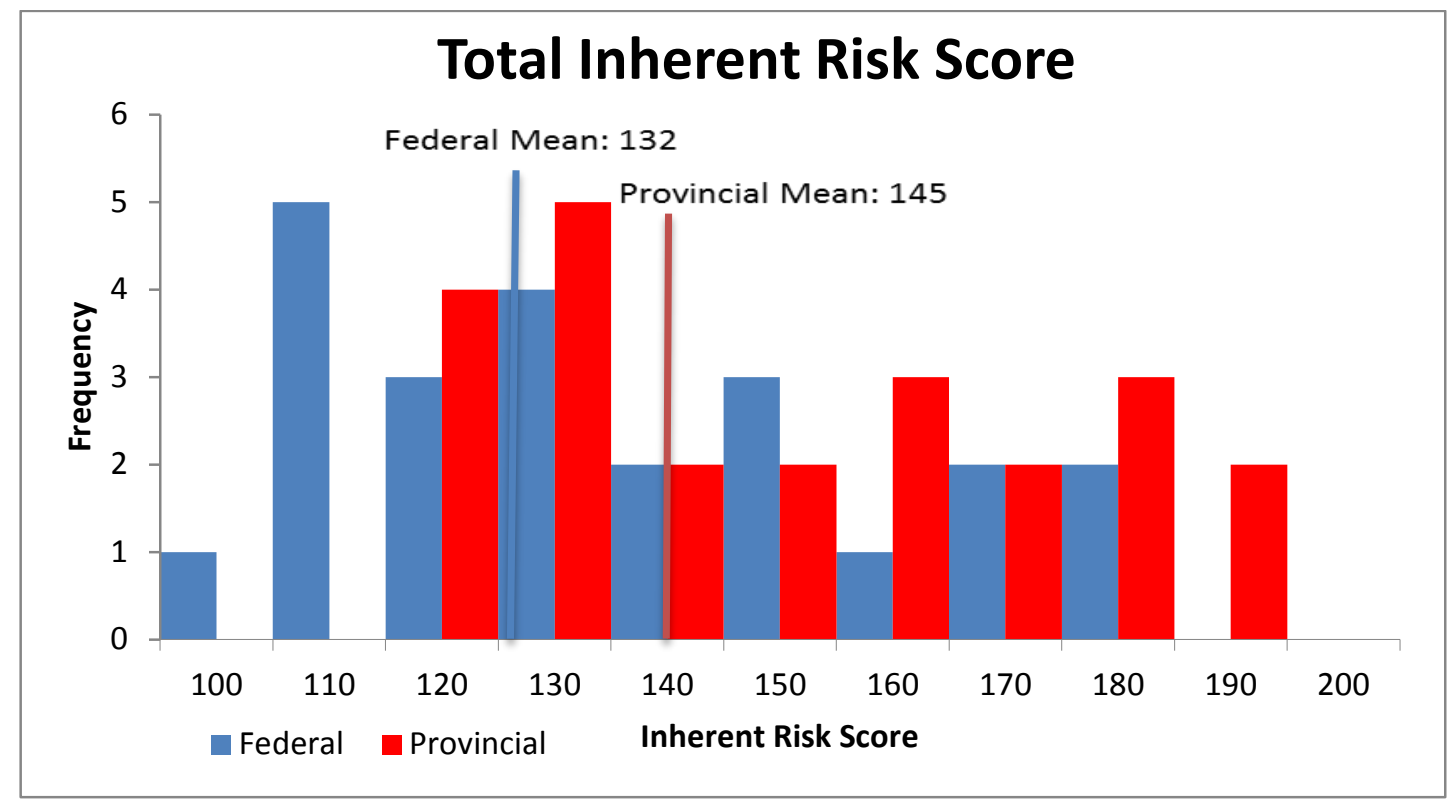

Figure 1 - Total Inherent Risk Score for federal (blue) and provincial (red) DPPs. Means are plotted for both. The figure shows there is a skew for provincial DPPs towards higher values when compared to federal dairies 
131.96 for federally registered ones, with a standard deviation of 24.35 and 24.14 respectively (Table 3 ). Provincially licensed dairies had a lower positive skew than federally registered ones. This suggests that federally registered dairies have lower total risk scores.

There was a difference in how dairies are clustered according to the frequency of risk scores from 100 to 200 in bins of 10 (Figure 1). For both, the risk scores most observed were to the lower end of the risk score spectrum, but provincially licensed dairies showed higher frequencies of higher risk scores. This can be seen visually as the frequency of the federally registered dairies becomes lower with increasing risk scores while the provincial ones stay relatively constant. This is numerically represented in Table 3 by the kurtosis; federally registered dairies have a more positive kurtosis value which is indicative of the heavier tail observed.

\section{Inferential Statistics}

Provincially licensed plants serve only the province of $\mathrm{BC}$ with dairy products while plants which are federally registered are able to export their products to other provinces and countries. As such, the following hypothesis were developed for the present study.

$H_{0}$ : There is no statistically significant difference between the inherent risk scores of provincially licensed dairies to those of federally registered ones

$H_{A}$ : There is a statistically significant increase in inherent risk score for provincially licensed dairies over federally registered dairies

These hypotheses were chosen based on the author's expectation that there would be more stringent controls to protect public health in federal plants due to the dairy products being exported out of country or province and to a potentially larger population.
The data was analyzed using a one tailed t-test in order to assess if there was a significant difference in the means between the provincially licensed and federally registered DPPs.

NCSS was used to analyze 46 out of a total of 54 DPPs. Of these 46, 23 represented provincially licensed plants and the remaining 23 were representative of the federally registered ones. While the data showed equal variance, it failed the test of normality which showed the data is not normally distributed. A Mann-Whitney $U \mathrm{t}$ test was used in response to this information in order to determine the significance of the data at the $\alpha=0.05$ level. The test showed that the $p$ value was 0.036 , which means that this result would have occurred $3.6 \%$ of the time by chance alone. Since this value is lower than the alpha level selected, $\mathrm{H}_{0}$ should be rejected as the data shows that federally registered $\mathrm{BC}$ dairies have a statistically significant lower risk score than provincially licensed BC dairies.

With respect to the research conducted here, a type I error can occur as the obtained $p$ value of 0.036 is relatively close to the selected $\alpha$ level of 0.05 . A lower $p$ value would have made the likelihood of a type I error occurring much less. With respect to a type II error, the sample size of dairies used was 46 out of a total possible of 54 . Since $85.2 \%$ of all dairies in BC were included in this research, a type II error is unlikely to occur and is low. Due to the low likelihood of a type II error occurring, the power of the present study should be considered higher than what was obtained in NCSS.

These data suggest there is a decreased total risk score for federally registered dairies when compared to provincially licensed dairies.

\section{Subsection Scores}


The plant location subsection of the survey was used to determine if the DPP had an on-site dairy farm. The highly ranked DPPs generally included those with

Table 4 - Subsection T Tests

an on-site farm while the lower ranked ones did not. Furthermore, most of these on-site dairy farms serve provincial DPPs. To investigate if this had been the reason for the increased inherent total risk score seen in provincial DPPs, an additional t-test was run for this subsection alone. The results showed that there was no significant difference in inherent risk score between the two licensing statuses.

In response to this finding, t-tests for the remaining subsections were to investigate if any had a significant contribution to the increased risk score seen amongst provincial DPPs. Table 4 below shows the result of these tests.

Subsections with the most significant differences in inherent risk score were plant premises $(p=0.001)$ and food safety management $(p=0.008)$. In addition, nondairy ingredients section also showed a relatively low $p$-value $(p=0.069)$ but still was above the $\alpha=0.05$ level. The plant premises subsection was used to determine if DPPs had incorporated the use of good production practices such as rating their water source,

\begin{tabular}{|c|c|c|}
\hline Subsection & p-value* & Increased Provincial Contribution? \\
\hline Company & & \\
\hline Information & 0.999 & No \\
\hline Plant Location & 0.211 & No \\
\hline Milk Source & 0.124 & No \\
\hline Non-Dairy & & \\
\hline Ingredients & 0.069 & No \\
\hline Plant Premises & 0.001 & Yes \\
\hline Food Safety & & \\
\hline $\begin{array}{l}\text { Management } \\
\text { Dairv Processing and }\end{array}$ & 0.008 & Yes \\
\hline Processing Control & 0.229 & No \\
\hline $\begin{array}{l}\text { Product Information } \\
\text { Finished Product }\end{array}$ & 0.852 & No \\
\hline Status & 0.535 & No \\
\hline
\end{tabular}

sewage management, visitor policies and worker hygiene. The food safety management subsection was involved with the determination of if facilities for certification and if safety programs are present.

While these two subsections showed a significant increase in inherent risk score for provincial DPPs when compared to federal ones, most subsections showed that provincial dairies had an overall positive skew.

\section{Discussion}

The present study used a semiquantitative method to characterize risk of DPPs based on survey response data. This was done by copying the survey information and pasting it into an excel sheet created for the present study. This resulted in the survey information being automatically interpreted in a standardized manner to produce the dairy's total risk score. Using excel to expedite this process has been done before, but those methods require extensive input of information to characterize risk by the individual and are not designed for characterizing risk based on extensive survey data (Ross, 2002). Additionally, the methodology used in the present study was also able to successfully

${ }^{*} \mu 1-\mu 2>0$ : (Provincial) - (Federal) $>0$ 
create a ranking similar to other semiquantitative studies. There was no evidence found in the literature that suggested the effect of licensing status (i.e. provincial licensing vs. federal registration) of DPPs on risk potential.

While the present study showed that federally registered have a lower intrinsic risk score, because those DPPs serve a larger population in a larger area they are likely to have a higher overall risk. In addition, federally registered DPPs generally manufacture greater volumes of product and employ more workers which can also confer a higher risk for that facility. Thus the result showing that provincial dairies in BC currently are of higher risk than those which are federal contrasts to what would have been expected.

Investigating further into the specific subsections showed that two subsections had statistically significant increased inherent risk scores. Despite this, it also showed that provincial dairies generally had higher scores than federal ones. The cumulative effect of adding these subsection scores then would likely have led to an overall increase in provincial dairy risk score that would be of higher significance than any subsection alone.

One explanation for this could be that provincial dairies have controls which are not managed as well as their federal counterparts. Federal dairies have a larger and much more global customer base. The implications for an outbreak for these federal dairies would be much greater than a provincial dairy, which ships to clients only within BC. As such management for the federal facilities would have more impetus to ensure that all critical control points are within specified limits.

Another observation which had not been expected was that there was no significant difference between inherent risk scores in the Plant Location subsection despite more provincial dairies having onsite farms than federal ones. Also of note is that these provincial farms scored a higher risk when compared to federal ones. Since these farms are potential sources of biological or chemical contamination this information should still be taken into consideration when creating an inspection frequency despite the statistical test showing there was no significant increase.

The present study showed the ability of Excel to be used to complete a semiquantitative risk assessment in a high throughput manner. This methodology can potentially be applied to other jurisdictions who are interested in conducting their own risk assessments based on survey information.

\section{Recommendations}

From the present study we can conclude to risk assessors that provincially licensed DPPs may have additional higher risk conditions when compared to federally registered DPPs. Dairy inspectors can use this information in tandem with their experience, lab results, inspection data and observational evidence to be able to create a new inspection frequency that is based on data relevant to the $\mathrm{BC}$ sector. Additionally, it allows inspectors to be more informed on potential risks of a facility so that they can work with operators to reduce the risks more efficiently.

Based on the ranking of the Plant Location subsection scores, DPPs which have an on-site farm have higher risk scores than those without farms. This could be attributed due to increased likelihood of contamination of product with fecal matter through run off, workers or any chemicals due to vehicle use from the farm. It can also be used to indicate higher risk DPPs, as a plant without a farm but with a high risk score yet would indicate that this is a relatively high risk facility when compared to other DPPs. Comparing subsection scores can provide the assessor with a stronger sense of what is happening at a dairy facility than just looking at the consolidated risk score alone.

Additionally, it is suggested that due to provincial dairies having a higher intrinsic risk score than other facilities additional dairy inspectors may be required to inspect these facilities. This would allow for inspection activities to meet a level sufficient to reduce the likelihood of a foodborne 
illness outbreak due to a provincially licensed dairy.

\section{Limitations}

The information found in the present study is only applicable to dairies in BC. This is due to the sample size used being relatively small, which prevents its use in a generalized risk assessment over larger jurisdictions despite being sufficient for provincial use. In addition, the excel tool was based on the BC legislation and guidelines. As such, modifications would be required for the same methodology to be used in any other province or country. This limitation could not be avoided due to scope of the present study being based only on the purpose to examine only $\mathrm{BC}$ dairies.

Due to time constraints, all DPPs were unable to be included in this study. While the majority of DPPs did complete their surveys the result may be unaffected, the study cannot conclude that based on the excel tool and survey information that all federally registered $\mathrm{BC}$ dairies have a lower risk than their provincially licensed counterparts. Had there been more time to include all dairies in the present study then this limitation would have been avoided.

The actual tool itself performs its task as it is scripted to; however, the assigning of risk scores and weightings for each category may be subjective and require subject expertise. While scientific data and literature sources were consulted for score assigning, there is a possibility that some scores were assigned subjectively thus affecting the end result. This should be considered in the final integration of the tool in the risk ranking system used by the BCCDC and corrections should be made if necessary. This limitation was avoided through constant checking of scripts as well as researching several sources in order to characterize the risk for one condition. Also, the potential for human error exists during tool scripting development. The relative complexity of the tool makes it difficult for anyone who is inexperienced in Excel to alter or change scripting information
Due to the tool being based on information gathered by an online survey, participants may have answered the questions incorrectly. If this was due to unclear questions, this could potentially affect many responses and have made results inaccurate. A possible way to have avoided this would be to use in person surveys to allow for clarification or to have the input information based on inspectors observing conditions themselves during inspections rather than relying on the dairy operators.

\section{Future Research}

Future studies can use the methodology applied in the present study in order to assess the validity and reliability of the research strategy used. This would provide a stronger proof of concept, whereupon the same methodology can be used to determine inspection frequencies for other types of facilities outside of dairy production.

Assessing the risks of all facilities across Canada can also potentially allow risk assessors to predict the locations at greatest risk of experiencing a food borne illness outbreak. If one location is served by a variety of relatively highly scored facilities, then that location has a higher likelihood of an outbreak occurring as opposed to a second location served by lower scored facilities. Demographics in these locations can then be looked at in order to assess the impact vulnerable populations and then these two pieces of information to then rank communities which are potentially at greatest risk. Should this be undertaken, it would provide public health inspectors in high risk communities with increased information that would allow the health units to distribute resources accordingly in order to manage a potential outbreak with a stronger and faster response than they otherwise may have been able to.

While the present study examined risk inherent to DPPs, improvements can be made to the risk-based inspection tool through including information on actual observed risk at the DPPs. This would require inspection information, food and 
environmental sampling results and information on management control. While a DPP may have a lower ranking, the above information can potentially increase risk score resulting in a need for increased inspections.

\section{Conclusion}

With any food borne illness outbreak being linked to a processing facility, it shows that there was a loss of control over the food product at some point during processing. This can potentially be prevented should that loss of control be related to a procedure that can be corrected through inspection. With Gort's Gouda Cheese farm being linked to an E. coli O157:H7 outbreak across Canada, an assessment of DPPs was done through an online survey. Respondent data was then input into an excel tool which allowed for the interpretation of a great amount of information in a few minutes using a semi quantitative risk assessment strategy. This allowed for the creation of a risk ranking of all dairy facilities which responded to the survey. The present study also succeeded in evaluating risks for provincially licensed DPPs as compared to their federally registered counterparts, which has not been performed previously. These data showed that provincially licensed plants without federal registration have a significantly higher inherent risk score $(p=0.036)$ than those with federal registration. The information obtained from the present study will provide a framework to risk assessors involved in dairy inspection to create a new inspection frequency schedule of dairies in $B C$. This inspection frequency will ensure that the likelihood of food borne illness outbreaks due to BC DPPs remains low.

\section{Acknowledgements}

The author would like to thank Jovana Kovacevic, Lynn Wilcott and Sion Shyng from the BCCDC for feedback regarding risk characterization, appropriate design of the excel tool and for securing as many survey responses in a limited time frame as possible. Within BCIT, assistance was given by Helen Heacock, Bobby Sidhu and Fred Shaw throughout the research process.

\section{Abbreviations}

\author{
BC: British Columbia \\ BCCDC: British Columbia Center for \\ Disease Control \\ DPP: Dairy Processing Plants
}

\section{Competing Interests}

The author has declared that he has no competing interest in the research topic. 


\section{References}

Allain J-P, Palmer CR, Pearson G. (1998)

Epidemiological study of latent and recent infection by Toxoplasma gondii in pregnant women from a regional population in the UK. Journal of Infection; 36: 189-196.

ANZFA. (2001) Raw Commodity Consumption Figures. Canberra: ANZFA

Baghurst K. (1999) Red meat consumption in Australia: intakes, contributions to nutrient intake and associated dietary patterns. European Journal of Cancer Prevention; 8: 185-191.

BCCDC (2014) Survey for BC Dairies for Inspection Frequencies. Information retrieved on September 27 2014.

Buchanan, R., \& Whiting, R. (1998). Risk Assessment: A Means for Linking HACCP Plans and Public Health.Journal of Food Protection, 61(11), 1531-1534. Retrieved October 10, 2014, from http://www.ingentaconnect.com/content /iafp/ifp/1998/00000061/00000011/art0 $\underline{0021}$

Cseke, P (2013) Inspecting Inspection Reports, Does the Type of Restaurant Change the Risk? Vancouver, $\mathrm{BC}$ : BCIT Environmental Health Journal.

FAOMHO [Food and Agriculture Organization of the United Nations/World Health Organization]. 2009. Risk Characterization of Microbiological Haards in Food: Guidelines. Microbiolocial Risk Assessment Series No. 17. Rome. $116 \mathrm{pp}$

Food Standards Agency. (FSA) Improved risk-based dairy inspections. (2011, March 1). Retrieved October 10, 2014, from http://www.food.gov.uk/newsupdates/news/2011/4740/dairyinspec
Heacock, H., Sidhu, B. (2014) Research methods module 5: Descriptive Statistics. Vancouver BC, BCIT. ENVH 8400 - Research Methods.

Fowle III, J. (2000). INTRODUCTION TO RISK CHARACTERIZATION. In Risk Characterization Handbook (p. 11). Washington, DC: Science Policy Council.

Lake, R., Hudson, A., \& On, S. (2009). Risk Profile: Mycobacterium bovis in Milk. Christchurch Newzealand: Institute of Environmental Science \& Research Limited.

Lake, R., Hudson, A., \& Cressey, P (2002). Risk Profile: Toxoplasma Gondii in Red Meat and Meat Products. Christchurch Newzealand: Institute of Environmental Science \& Research Limited.

McIntyre, L. (2014) Interview with Lorraine McIntye (EHS) on survey data. Information retrieved on September $27^{\text {th }}, 2014$.

Milk Industry Act. (2014, October 8). Retrieved October 12, 2014, from http://www.bclaws.ca/Recon/document/ ID/freeside/00_96289_01

Milk Industry Standards Regulation. (2013, December 12). Retrieved October 12, 2014, from www.bclaws.ca/EPLibraries/bclaws_ne w/document/ID/freeside/464_81

NCSS: Statistical \& Power Analysis Software. (2007). Accessed November 13, 2014. Website: www.ncss.com/

Nikolić, B. (2012). A NEW RISK ASSESSMENT METHOD. In MONITORING AND EXPERTISE IN SAFETY ENGINEERING (1st ed., Vol. 2, p. 11). ST. PETERSBURG: St. Petersburg University of State Fire Service of EMERCOM of Russia. 
Public Health Act (2014, October 8). Retrieved October 12, 2014, from http://www.bclaws.ca/Recon/document/ ID/freeside/00 0802801

PHAC. (2013, November 15). Public Health Notice - E. coli O157:H7 illness related to cheese produced by Gourt's Gouda Cheese Farm. Retrieved October 13, 2014, from http://www.phacaspc.gc.ca/fs-sa/phn-asp/2013/ecoli0913-eng.php

Risk Analysis (USDA). (2013, August 9). Retrieved October 10, 2010, from http://www.fsis.usda.gov/wps/portal/fsis/ topics/food-safety-education/getanswers/food-safety-factsheets/production-and-inspection/riskanalysis/risk-analysis

Ross, T., \& Sumner, J. (n.d.). A simple, spreadsheet-based, food safety risk

assessment tool.International Journal of Food Microbiology, 39-53.

Sampers, I., Toyofuku, H., Luning, P., Uyttendaele, M., \& Jacxsens, L. (2012). Semi-quantitative study to evaluate the performance of a HACCP-based food safety management system in Japanese milk processing plants. Food Control, 23(1), 227-233.

Shi Y. (2014) Creating Premise Risk Assessments for Dairy Processing plants in $\mathrm{BC}$

Van Gerwen, S., Te Giffel, M., Van 't Riet, K., Beumer, R., \& Zwietering, M. (2001). Stepwise Quantitative Risk Assessment As A Tool For Characterization Of Microbiological Food Safety.Journal of Applied Microbiology, 938-951. Retrieved October 18, 2014.

Woodruff, J. (2005). Consequence and likelihood in risk estimation: A matter of balance in UK health and safety risk assessment practice. Safety Science, 345-353. Retrieved October 18, 2014.

Wilcott L., (2014) Interview with Lynn Wilcott (Director of Food Protection Services). Information retrieved on September $27^{\text {th }}, 2014$. 